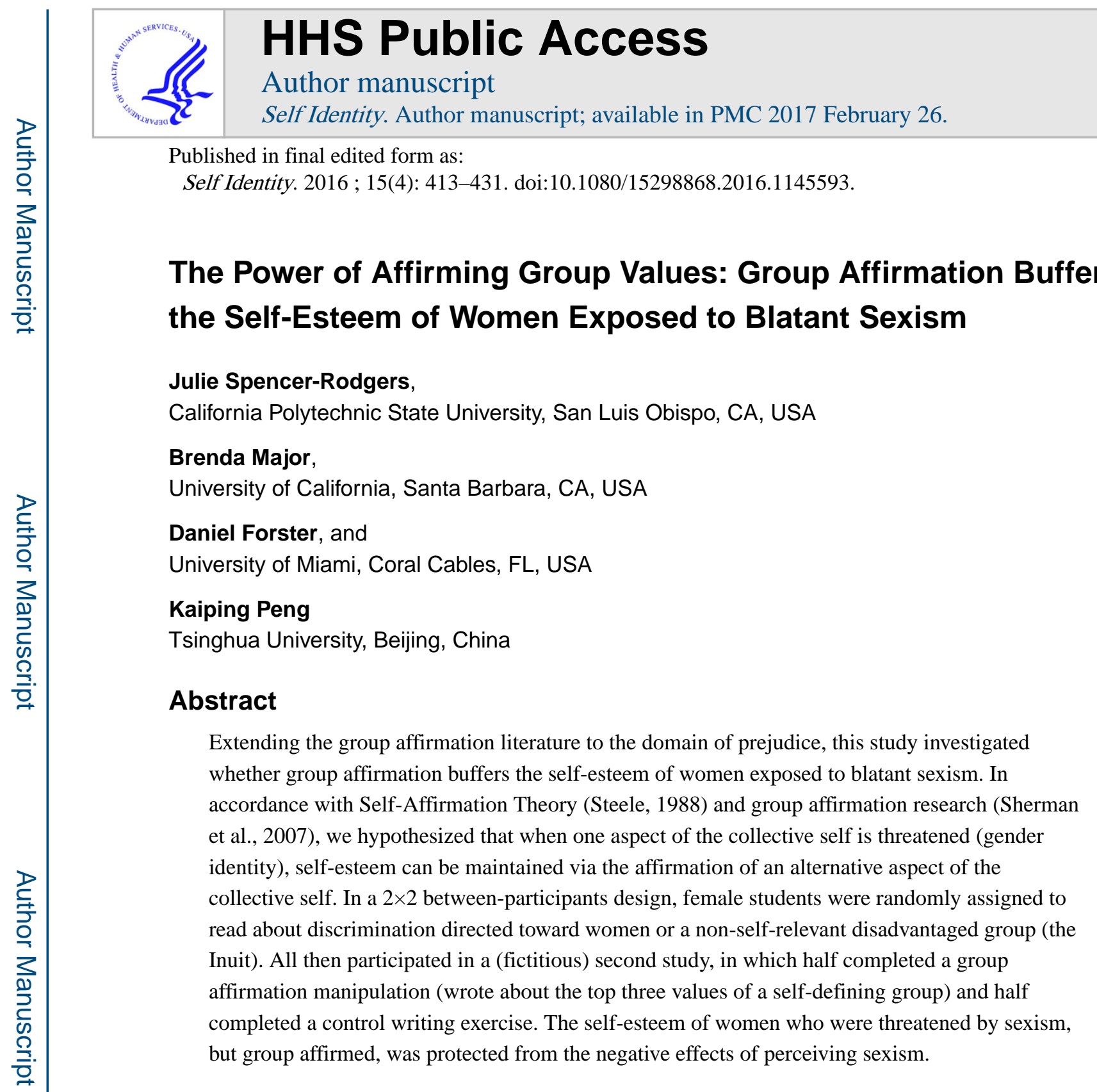

\title{
Keywords
}

sexism; group affirmation; self-esteem; gender identity

\begin{abstract}
Despite great strides in numbers in higher education and the labor market, American women continue to confront sexism at the institutional and interpersonal levels (Collins, 2002; Nadal \& Haynes, 2012; Nutt, 2010). Female college graduates in the United States (US) now outnumber their male counterparts, with $57 \%$ of college degrees being granted to women (National Center for Education Statistics, 2011) and close to half of the US workforce is female (47\%; Women in the Labor Force, 2010). Nonetheless, one year after receiving their
\end{abstract}

\footnotetext{
Corresponding author: Dr. Julie Spencer-Rodgers, Department of Psychology and Child Development, California Polytechnic State University, San Luis Obispo, CA, 93405, jsrodger@calpoly.edu.

Declaration of Conflict of Interest:

The author(s) declared no potential conflicts of interests with respect to the authorship and/or publication of this article.
} 
diplomas, female alumni working full-time will earn only 82 cents for every dollar that male alumni working full-time earn. This gender gap in wages is expected to persist throughout their careers, in part, because women have fewer opportunities for advancement (Corbett \& Hill, 2012). And while in college, female students report experiencing sexism in the form of stereotypic remarks made by male students and faculty (Nicholson, 2002; Nutt, 2010). Is the self-esteem of young women harmed when they learn about pervasive sexism on college campuses and in the workforce? And if so, how can this risk of psychological harm be mitigated?

\section{Perceived Sexism and Self-Esteem}

The relationship between perceptions of sexism and self-esteem is complex. On the one hand, recognizing and acknowledging sexism has numerous benefits for women. Being aware of sexism in society, attributing negative outcomes to discrimination (rather than to personal failings; Crocker \& Major, 1989; Crocker, Major, \& Steele, 1998), and directly confronting chauvinists can be highly empowering and self-protective (Ayres, Friedman, \& Leaper, 2009; Gervais, Hillard, \& Vescio, 2010). Being aware of gender-based stereotype threat can improve math performance (Johns, Schmader, \& Matens, 2005) and knowledge of sexism can lead to greater collective action on behalf of women as a group (Foster, 2000). On the other hand, sexism can be a poignant and painful threat to the self. Numerous studies have documented that perceived pervasive sexism and gender-based stereotype threat are related to lower self-esteem, greater psychological distress (e.g., anxiety, depression, etc.), physiological stress, physical health problems, and poor performance (Branscombe, Kobryknowicz, Owen, \& Schmitt, 2002; Dion, 1975; Eliezer, Major, \& Mendes, 2010; Fischer \& Holtz, 2007; Hunter, 1998; Logel, Walton, Spencer, Iserman, von Hippel, \& Bell, 2009); McCoy \& Major, 2003; Pascoe \& Richman, 2009; Schmitt, Branscombe, \& Postmes, 2003; Schmitt, Branscombe, Postmes, \& Garcia, 2014; Swim, Hyers, Cohen, \& Ferguson, 2001). Here, we examine one strategy that may promote resilience among women exposed to pervasive sexism - group affirmation.

\section{Self- and Group Affirmation}

According to Self-Affirmation Theory (Steele, 1988), when one aspect of the self-concept is threatened (e.g., appearance self-esteem), the integrity of the self can be maintained via the active affirming or bolstering of another central aspect of the self-concept (e.g., academic self-esteem). Self-affirmation is one of the most robust and widely-used interventions in the fields of health, clinical, and social psychology (Cohen et al., 2009; McQueen \& Klein, 2006; Sherman \& Cohen, 2006). When people are threatened or exposed to stressful stimuli, self-affirmation can buffer self-esteem (Fein \& Spencer, 1997), improve cognitive and academic performance (Cohen et al., 2009; Jones, 2011; Legault, Al-Khindi, \& Inzlicht, 2012; Sherman et al., 2013), and reduce cortisol and epinephrine levels (Creswell et al., 2005; Sherman, Bunyan, Creswell, \& Jaremka, 2009).

Although far less studied, other research suggests that when people experience a threat to an aspect of their "collective self" (i.e., one of their social identities; Brewer \& Gardner, 1996; Tajfel \& Turner, 1986), actively bolstering or affirming that social identity or an alternative 
social identity (i.e., another component of the collective self) can also reduce threat (Derks, van Laar, \& Ellemers, 2006; Rydell, McConnell, \& Beilock, 2009; Sherman, Kinias, Major, Kim, \& Prenovost, 2007; Tajfel \& Turner, 1986). For example, Sherman et al. (2007) showed that engaging in a group affirmation bolsters psychological resources and reduces defensive responses to social identity threat, such as group-serving biases. UCSB athletes wrote about why three of their team's values were important to their team (group affirmation). Relative to no-affirmation controls, the group-affirmed athletes were more receptive to threatening information about their group (their team losing a game) and more likely to attribute failure to their own team's poor performance. Group affirmation has been further examined in the context of stereotype threat (Derks, Scheepers, van Laar, \& Ellemers, 2011). Using a parallel-parking video simulation, Derks and colleagues exposed women to stereotype threat regarding women's allegedly poor parking ability. Group affirmation (receiving positive feedback about their gender) reduced physiological stress among highly gender-identified women who were stereotype threatened. Similarly, group affirmation (affirming a dimension on which women excel) led women to feel more confident in a mixed-gender performance situation (Derks et al., 2006). When female college students were exposed to gender-based stereotype threat (e.g. they were told "women are generally worse at math than men," Rydell et al., 2009, pg. 954), they performed better in the face of this threat when an alternative, positively-stereotyped social identity was accessible (e.g., they were told "college students are generally better at math than those not in college", pg. 954), demonstrating the self-protective properties of emphasizing alternative aspects of the "collective self".

The current study contributed to the literature on group affirmation in numerous ways. In almost all prior group affirmation studies, the participants were instructed to affirm the threatened group or an alternative dimension of the threatened group (for an exception, see White, Argo, \& Sengupta, 2012). Paralleling Self-Affirmation Theory (Steele, 1988), in which affirmations are thought to be most effective when alternative aspects of the selfconcept are affirmed (e.g., academic self-esteem is affirmed when appearance self-esteem is threatened), we reasoned that people might benefit from affirming alternative aspects of the collective self (i.e., alternative group identities) when one important group identity is threatened (i.e., gender identity). Furthermore, the current research is novel in that we allowed people to freely choose the groups they wished to affirm. Notably, the majority of women in our study generated and affirmed a different group membership, rather than the group identity under threat ("women"). In addition, we classified the freely-generated groups according to Lickel et al.'s group typology (i.e., social category, intimacy group, task group, or loose association; Lickel, Hamilton, Wieczorkowska, Lewis, Sherman, \& Uhles, 2000). When given the opportunity, most of the women chose to affirm highly entitative groups, namely intimacy groups and task groups, rather than broad social categories such as "women" and "college students." Thus, the findings demonstrate the self-protective properties of affirming a wide variety of types of groups. Lastly, this study extended research on the topic of group affirmation to the domain of prejudice and investigated whether group affirmation protects self-esteem in the face of perceived pervasive sexism.

Social Identity Theory (e.g., social creativity; Tajfel \& Turner, 1986) and the Rejection Identification Model (Branscombe, Harvey, \& Schmidt, 1999) argue that psychological well- 
being (including self-esteem) can be buffered by increasing identification with the threatened ingroup. The construct of group affirmation ("affirming an important ingroup value"; Sherman et al., 2007, pg. 1100) extends these theories by asking people to actively bolster or "affirm" a group value, rather than relying on individual differences in the propensity to spontaneously engage in group affirmation as a method of self-protection. Further, contrary to social identity theory, group affirmation does not necessarily involve ingroup/outgroup comparison processes (Sherman et al., 2007). The construct of group affirmation also differs from the Rejection-Identification Model (Branscombe et al., 1999) in that group affirmation proposes that bolstering and affirming alternative groups can be buffering (rather than increasing identification with the threatened group).

\section{The present study}

We first manipulated perceptions of discrimination by having female college students read a (fabricated) news article about blatant discrimination directed toward women in college and the workforce. This manipulation and its variants (McCoy \& Major, 2003) reliably produce psychological distress, including increased anxiety (Eliezer et al., 2010) and negative affect (Shelton, Richeson, \& Salvatore, 2005), slower physiological recovery (Eliezer et al., 2010) and lower self-esteem (Schmitt et al., 2003). Control participants read about severe discrimination directed toward the Inuit, a non-self-relevant disadvantaged group. Half of the participants then engaged in a group affirmation task, and half engaged in a control task. Thus, the study employed a 2 (Type of Article: Inuit control, Sexism manipulation) $\times 2$ (Affirm: No-affirmation, Group-affirmation) between-participants design, resulting in four cells: $1=$ Inuit/No-affirm; 2 = Inuit/Affirm; $3=$ Sexism/No-affirm; and $4=$ Sexism/Affirm. The purpose of the Inuit control conditions was to determine if the self-esteem of women who were exposed to sexism, but group affirmed, was fully buffered or "restored" to the level of the control participants (figuratively speaking, as this a between-participants and not a within-participants design).

Previous studies have shown that self-affirmations are most effective: 1) when they are indirect, that is, when the affirmed domain is unrelated to the threatened domain (e.g., appearance self-esteem is affirmed when academic self-esteem is threatened), 2) when the threatened domain is central and important to the self-concept, 3) when the affirmed domain is likewise important to the self-concept, and 4) when affirmations operate outside of conscious awareness (i.e., when people are unaware of their intended influence on behavior: Sherman \& Cohen, 2006; Sherman, Cohen, et al., 2009; although see Silverman, Logel, \& Cohen, 2013). Extrapolating to the group-level, we anticipated that women could draw upon unrelated, but valuable group memberships (e.g., one's membership in a sorority) in order to maintain self-worth in the face of a threat to social identity (in this case, gender identity).

To test this hypothesis, we developed a group affirmation manipulation based on work by Sherman et al. (2007) and McGregor, Haji, and Kang (2008). As outlined earlier, affirmations are most effective if the threatened domain (i.e., gender identity) is central and important to the self. Therefore, we prescreened participants and only recruited women who reported relatively high scores on a measure of gender centrality (Luhtanen \& Crocker, 1992). To ensure that the alternative, affirmed group was likewise important to the self, the 
women selected a group of their choice with whom they felt very close and shared common values (e.g., a group of roommates, their sorority, basketball team). Women in the group affirmation condition then selected three values and wrote about how the values were important to that group. Control participants completed a neutral writing exercise (Cohen, Aronson, \& Steele, 2000). To reduce awareness and suspicion, the sexism and affirmation manipulations were presented as two ostensibly separate studies, with the sexism manipulation presented in the "first study."

\section{Hypotheses}

Because we had well-articulated, a priori theoretical hypotheses about the expected differences in all 4 cell means, we formulated our statistical hypotheses in terms of focused planned comparisons.

First, in accordance with prior research (Schmitt et al, 2003), we predicted that the sexism manipulation would have a negative effect on self-esteem in the absence of the group affirmation. That is, we expected women who read about pervasive sexism and were nonaffirmed (Sexism/No-affirm) would have significantly lower self-esteem than non-affirmed women who read about pervasive discrimination toward the Inuit (Inuit/No-affirm). We conducted a planned comparison to test this hypothesis. This analysis essentially served as a check on the sexism manipulation.

Second, we predicted that if the group affirmation is effective in preserving self-integrity and buffering self-esteem, then women who are threatened by sexism, but group affirmed (Sexism/Affirm), would have higher self-esteem than women who are threatened by sexism, but non-affirmed (Sexism/No-affirm). We conducted a planned comparison to test this hypothesis.

The Inuit control conditions were included to serve as a baseline to assess whether the group affirmation fully "restores" self-esteem (figuratively speaking). Although one can neither predict nor confirm the null hypothesis (Fisher, 1966), if the group affirmation fully restores the self-esteem of people under threat, then we would expect that the self-esteem of women who were exposed to sexism, but group affirmed (cell 4: Sexism/Affirm), would be roughly equal to that of women in the Inuit control conditions (cell 1: Inuit/No-affirm and cell 2: Inuit/Affirm). That is, cell 4 should not differ from cells 1 and 2. Alternatively, if cell 4 is significantly lower than cells 1 and 2 , then this would suggest that the group affirmation did not completely restore self-esteem. We conducted a planned comparison to test whether the mean of cell 4 was lower than the average of cells 1 and 2.

\section{Alternative Potential Explanations}

Affirmations are thought to operate by boosting psychological resources (Steele, 1998; Steele, Spencer, \& Lynch, 1993). In the case of group affirmation, these psychological resources are afforded by contemplating membership in the affirmed group (Sherman et al., 2007). However, one might argue that the predicted esteem-buffering effect (among women in the Sexism/Affirm vs. Sexism/No-affirm conditions) could be due to increased gender identification, rather than to group affirmation. This alternative explanation is derived from 
the Rejection-Identification Model (Branscombe et al., 1999), which posits that perceived discrimination leads to greater identification with the threatened group, which in turn, leads to greater psychological wellbeing (including self-esteem) in the face of prejudice. Another, albeit less plausible, alternative explanation for the predicted esteem-buffing effect (among women in the Sexism/Affirm vs. Sexism/No-affirm conditions) is gender disidentification: the women might simply detach from and/or devalue their gender group when threatened by discrimination (Tajfel \& Turner, 1986). This is unlikely, given that all of our participants were initially high in gender identity (based on prescreening), and high group-identifiers tend to strengthen their attachment to the disadvantaged group in the face of prejudice (Allport, 1954; Branscombe et al., 1999; McCoy \& Major, 2003; Tajfel \& Turner, 1986).

Nonetheless, to test these two possible alternative explanations, we repeated the self-esteem analysis comparing the Sexism/Affirm to the Sexism/No-affirm condition, controlling for gender identity (and gender liking). Specifically, if the esteem-buffering effect were due to gender identity, then one would expect the predicted self-esteem effect to disappear or weaken when controlling for this variable. We also compared the gender identity (and gender liking) scores of women in the Sexism/Affirm versus the Sexism/No-affirm conditions. If gender identification were to account for the predicted higher self-esteem in the Sexism/Affirm than Sexism/No-affirm condition, we also would expect gender identity to be higher in the Sexism/Affirm than in the Sexism/No-affirm condition. (The opposite pattern would be expected for group disidentification: gender identity should be lower in the Sexism/Affirm than in the Sexism/No-affirm condition.)

\section{Method}

\section{Participants}

Participants were $\mathrm{N}=151$ European-American female undergraduate students $\left(M_{\mathrm{age}}=19.6\right.$, $S D=1.7$ ) at a West coast university who participated for course credit or $\$ 10$. All participants previously had completed online prescreening measures, including two items measuring identity centrality (Luhtanen \& Crocker, 1992), with items rated on a 1 (completely disagree) to 7 (completely agree) scale and phrased to assess gender (e.g., "Being a member of my gender group is an important reflection of who I am"). To select highly genderidentified women, only women who responded above the 4.0 midpoint were eligible to participate. Because we anticipated there would be too few ethnic minority students in the sample to conduct meaningful analyses by ethnicity, we focused on recruiting women who self-identified as European-American during prescreening.

\section{Procedures}

"First" study-Women completed the study in small same-sex groups (3-6). They were greeted by an experimenter (European-American male) who explained they would be completing two short studies that day. Participants were told the first study (entitled "Internet Communication") was about "how information obtained online is processed... and how the framing of news information influences people's...retention of information." They were instructed the first study would take approximately 15 minutes and that a second experimenter would arrive later to conduct the second study. 
Participants were provided with an informed consent form, verbal and written instructions, and a questionnaire packet that contained two online news articles that ostensibly appeared in the San Francisco Chronicle (complete with surrounding advertisements and links to relevant stories). To bolster the cover story, participants first read and answered questions about a filler article about recycling in the United States. They then read the target article (Inuit or Sexism).

Sexism manipulation-We employed a discrimination manipulation adapted from McCoy and Major (2003). The experimenter (blind to condition) randomly assigned women to one of two conditions. In the experimental condition, women read about severe and pervasive discrimination directed toward women (female college students/alumni). The news article reported the results of a survey conducted by the (fictitious) California Research Consortium that found that women experienced widespread discrimination in college and during their careers (e.g., frequent sexist stereotypes, lower earnings than men, etc.). In the control condition, women read about an unfamiliar and non-self-relevant group (Inuit students/alumni of the University of British Columbia [UBC], Canada). The articles were identical in every respect except for the name of the target group discussed. We expected that reading about how discrimination affects the Inuit would activate general thoughts and feelings about prejudice, but would not constitute a significant threat.

Participants were instructed to read the articles carefully and refrain from looking at them when responding to questions. To ensure participants had encoded the information, as a manipulation check, they briefly summarized their content in writing. They then completed several filler questions. To ensure the Sexism and Inuit articles were equally potent, participants completed two items, rated on a 1 (not at all) to 7 (very much) scale. In the sexism condition, they rated: "According to the article, to what extent do female UC students experience sexism?" and “...to what extent do female UC alumni experience gender discrimination in the work force?" In the Inuit condition, they rated: "According to the article, to what extent do Inuit UBC students experience racism?" and "...to what extent do Inuit UBC alumni experience ethnic discrimination in the work force?" Participants also rated the quality of the article, specifically how understandable and well-written it was $(a=$. 64), on a 1 (not at all) to 7 (very) scale. When all participants had completed the packets (including demographic information), the experimenter retrieved them and exited the room.

"Second" study—The experimenter (European-American female) for the "second" study entered the room and explained the next study (entitled "Expressive Writing") was about "the influence of expressive writing on people's thoughts and feelings." Participants were provided with an informed consent form, verbal and written instructions, and a questionnaire packet.

Affirmation manipulation-The experimenter (blind to condition) randomly assigned the women to one of two conditions. Women in the affirmation-condition were instructed to "think about a group of people with whom you feel very close and share common goals. Please write down the first group of this kind that comes to mind." Next, they read through a list of 12 values and selected the three values most important to that group (Sherman et al., 2007). They were instructed to write a minimum of three paragraphs describing the group, 
the group's three important values (providing concrete examples of how the group has demonstrated the values; Sherman et al., 2007), and why belonging to the group was important to them (McGregor et al., 2008). Controls wrote a minimum of three paragraphs about the food/beverages they had consumed in the last 48 hours (Cohen et al., 2000). The writing task took approximately 10 minutes.

Participants then completed a questionnaire packet. Self-esteem (Cronbach's a=.90) was assessed with the Rosenberg Self-Esteem Scale (Rosenberg, 1965), with items rated on a 1 (not at all) to 7 (very much) scale, and phrased to assess state self-esteem (e.g., "At this moment, I am satisfied with myself"). Gender identity ( $a=.68)$ was measured with the Identity Centrality Subscale (Luhtanen \& Crocker, 1992), with items rated on a 1 (strongly disagree) to 7 (strongly agree) scale, and phrased to assess gender ("Being a member of my gender group is an important reflection of who I am"). Private regard (liking for one's gender; $\mathrm{a}=.62$ ) was assessed with the Private Regard Subscale (Luhtanen \& Crocker, 1992), with items rated on a 1 (strongly disagree) to 7 (strongly agree) scale ("In general, I am glad to be a woman"). Participants then completed several measures unrelated to this study and an open-ended probe for suspicion.

At the end of the study session, participants were asked to recall the article they had read about in the (bogus) first study. To ensure that the discrimination (Sexism and Inuit) articles were equally convincing, they rated the article's accuracy on a 1 (not at all accurate) to 7 (very accurate) scale, the article's credibility on a 1 (not all credible) to 7 (very credible), and the author's bias on a 1 (not at all biased) to 7 (very biased) scale (reverse-scored). The three items were combined $(a=.74)$. Lastly, participants were probed for suspicion by the experimenter and thoroughly and sensitively debriefed.

\section{Results}

\section{Preliminary Analyses}

Two participants who did not follow the instructions (see affirmation manipulation check) were excluded from the analyses. Because the study focused on young college-aged women, one participant who was substantially older than the sample mean (>7 SDs) was excluded. Six participants who indicated during debriefing they suspected the study was about sexism before they completed the dependent variables were also excluded ( 1 in Inuit/Affirm condition; 2 in Inuit/No-affirm condition; 1 in Sexism/Affirm condition; 2 in Sexism/Noaffirm condition). The final sample consisted of $\mathrm{N}=142 .{ }^{1}$

Stimulus materials-The sexism and Inuit articles were perceived as equally convincing and potent (see Table 1). Although identical in content, participants rated the sexism article ( $M=5.72, S D=0.63$ ) as higher in quality (understandable; well-written) than the Inuit article $(M=5.41, S D=.96), F(1,138)=5.13, p=0.025, \eta_{p}{ }^{2}=.04$. There was no main effect of affirmation, $F(1,138)=0.46, p=0.50, \eta_{p}{ }^{2}=.003$, nor interaction, $F(1,138)=0.41, p=0.52$, $\eta_{p}{ }^{2}=.003$. Consequently, we controlled for perceived article quality in all of the following analyses. $^{2}$

\footnotetext{
${ }^{1}$ All hypotheses were reanalyzed including these participants, and the pattern of results was the same.
} 
Sexism manipulation check-As a check to ensure participants had read the articles and encoded the information, they were asked to briefly summarize their content. Two research assistants (blind to affirmation-condition and the study hypotheses) verified that all participants correctly described the articles as being about sexism (experimental condition) or discrimination toward the Inuit (control condition).

Affirmation manipulation check-Following standard procedures in self-affirmation research (McQueen \& Klein, 2006), the essays were examined by two research assistants to ensure participants had followed the study instructions. In addition, they ensured that participants in the no-affirmation condition (who had been asked to write about food/ beverage consumption) had not spontaneously group affirmed or self-affirmed, as people may spontaneously affirm when threatened (Creswell, Lam, Stanton, et al., 2007). Two participants who did not follow the instructions were excluded. All remaining participants wrote a minimum of 2 paragraphs, either affirming the group they had selected to write about (affirmation-condition) or describing the food/beverages they had consumed (control condition).

Types of groups affirmed-The types of groups most frequently affirmed were: groups of friends/roommates ( $41 \%$ of participants), social and school-based clubs/organizations (12\%, e.g., sororities), families (12\%), college majors/students (10\%, e.g., Communication Majors), sports groups/athletes (8\%, e.g., basketball team), environmentalists/environmental organizations (6\%), religious groups (4\%), women $(4 \%)^{3}$, and others (3\%). A chi-square test indicated no difference in the types of groups affirmed by discrimination-condition (Inuit vs. sexism), $\chi^{2}(8, N=73)=8.58, p=.38$.

The groups were further categorized according to Lickel et al.'s (2000) typology (i.e., social categories, intimacy groups, task groups, and loose associations). The most frequently affirmed types of groups were: $62 \%$ intimacy groups (e.g., groups of friends/roommates), $19 \%$ task groups (e.g., basketball team), and 19\% social categories (e.g., college majors/ students, religious groups). A chi-square analysis revealed no difference by discriminationcondition (Inuit vs. sexism): $\chi^{2}(2, N=73)=3.72, p=.16$.

Types of values-Participants were instructed to select three from a list of 12 values: artistic skills/aesthetic appreciation, sense of humor, loyalty/commitment, spontaneity/living life in the moment, honesty/open communication, music ability/appreciation, sharing/giving, physical fitness/health, political activism, spirituality/faith, volunteerism, and support/ encouragement. The values most frequently selected first were: loyalty/commitment (40\% of participants), sense of humor (35\%), spontaneity/living life in the moment (6\%), and honesty/open communication (6\%). A chi-square test indicated no difference by discrimination-condition (Inuit vs. sexism): $\chi^{2}(9, N=72)=8.03, p=.53$.

\footnotetext{
${ }^{2}$ All hypotheses were reanalyzed without the quality covariate. The pattern of results was the same, except: The main effect of type of article on identity centrality was significant, $F(1,138)=4.42, p=.037, \eta_{p}^{2}=.03$.

${ }^{3}$ The pattern of results was the same without participants who affirmed the group "women".
} 


\section{Main Analyses}

Self-esteem-The mean self-esteem scores are presented by type of article and affirmation-condition in Figure 1. Because we had focused, a priori hypotheses about the expected differences in cell means, we conducted planned comparisons rather than a general analysis of covariance (ANCOVA) (Seltman, 2013). We followed the rule that $(g-1)$ planned nonorthogonal comparisons are permissible, without adjusting the per comparison alpha-level, where $g=$ number of groups (Gonzalez, 2013; Keppel, Saufley, \& Tokunaga, 1992; Pierce, 2003). In this case, $g=4$ cells, and 3 planned comparisons are permissible. The omnibus $F$-test was significant, $F(3,136)=4.16, p=.007, \eta^{2}=.08$, indicating that the overall model was significant.

First, as shown in Figure 1, replicating previous research (Schmitt et al., 2003), the pervasive sexism manipulation had a deleterious effect on self-esteem, in the absence of the group affirmation: women who read about pervasive sexism (and non-affirmed) had lower selfesteem than women who read about pervasive discrimination toward the Inuit (and nonaffirmed), $F(1,137)=6.78, p=.01, \eta_{p}^{2}=.05$.

Second, as predicted, the group affirmation effectively buffered self-esteem: women exposed to sexism, but group affirmed, had higher self-esteem than women exposed to sexism and non-affirmed, $F(1,137)=4.69, p=.032, \eta_{p}^{2}=.03$.

Third, the final planned comparison indicated that the self-esteem of women in cell 4 (Sexism/Affirm) did not differ from that of women in the Inuit control conditions (the average of Inuit/No-Affirm and Inuit/Affirm), $F(1,137)=1.07, p=.30, \eta_{p}^{2}=.008$. Although one can neither predict nor confirm the null hypothesis (Fisher, 1966) and nonsignificant findings are difficult to interpret, these results suggest that the self-esteem of women who were exposed to sexism, but group affirmed, was comparable to that of women in the control conditions. Figuratively speaking, their self-esteem was fully buffered or "restored".

\section{Alternative Potential Explanations}

As noted above, it is possible that the esteem-buffering effect among women in the Sexism/ Affirm condition compared to those in the Sexism/No-affirm condition could be due to increased (or decreased) gender identity, rather than to group affirmation. Because we did not have an a priori hypothesis about the specific pattern of means in all 4 cells, we conducted ANCOVAs (controlling for perceived article quality ${ }^{2}$ ), followed by post-hoc multiple comparisons on the measures of gender identity and private regard. Figure 2 presents the mean self-esteem, gender identity, and gender liking (standardized) scores for women who were threatened by sexism and either group affirmed or non-affirmed. (For ease of presentation, the Inuit control conditions were excluded.)

Gender identity-There was a marginal main effect of type of article on gender identity: Women who read about sexism $(M=5.88, S E=0.11)$ tended to be more strongly genderidentified than women who read about the Inuit $(M=5.56, S E=0.12), F(1,136)=3.55, p=$. $062, \eta_{p}{ }^{2}=.03$. However, there was no main effect of affirmation, $F(1,136)=.00, p=0.97$, 
$\eta_{p}{ }^{2}=.00$, nor interaction, $F(1,136)=.01, p=0.93, \eta_{p}{ }^{2}=.00$. Post-hoc multiple comparisons (Bonferroni) revealed that none of the 4 group means differed from each other ( $p$ 's $>.98)$.

Private regard-There was a main effect of type of article on private regard: Women who read about blatant sexism $(M=6.32, S E=0.11)$ reported significantly higher private regard (liking toward women) than did women who read about blatant discrimination directed toward the Inuit $(M=5.95, S E=0.11), F(1,137)=6.20, p=.014, \eta_{p}{ }^{2}=.04$. Again, however, there was no main effect of affirmation, $F(1,137)=0.88, p=0.35, \eta_{p}{ }^{2}=.006$, nor interaction, $F(1,137)=0.00, p=.96, \eta_{p}{ }^{2}=.00$. Post-hoc multiple comparisons (Bonferroni) indicated that none of the 4 group means differed from each other ( $p$ 's $>0.094)$.

Thus, as illustrated in Figure 2, women in the Sexism/Affirm and Sexism/No-affirm conditions did not differ with respect to either gender identity or private regard. This suggests that the esteem-buffering effect of group affirmation on women exposed to sexism (planned comparison Sexism/Affirm > Sexism/No-affirm) was not simply due to increased (or decreased) gender identification. Furthermore, this effect remained significant when we repeated this comparison including gender identity as a covariate, $F(1,136)=4.70, p=.032$, $\eta_{p}{ }^{2}=.03$, and when we included private regard as a covariate, $F(1,136)=4.24, p=.041, \eta_{p}{ }^{2}=$. 03 .

\section{Discussion}

Despite great strides in education and the work force, sexism continues to impact the lives of young women in the United States (Collins, 2002; Nadal \& Haynes, 2012; Nutt, 2010). Besides the burden of experiencing discrimination firsthand, young women and adolescents are exposed to sexism indirectly via the news and entertainment industries (Collins, 2002; Nutt, 2010; Zhang et al., 2009), all of which can reduce motivation and self-efficacy, and lead to disengagement from academics, avoidance of male-dominated careers, and the decision to opt out of the workforce altogether (Major \& Schmader, 1998; Major \& O'Brien, 2005; Zhang et al., 2009). One topic of debate is the extent to which young women should be educated about sexism (Collins, 2002), especially given that they underestimate its prevalence in society, the likelihood of their personally experiencing it, and the assertiveness of their responses to its perpetrators (Crosby, 1984; Sipe et al., 2009; Taylor, Wright, Moghaddam, \& Lalonde, 1990). Some argue that overlooking discrimination and downplaying its importance in one's life is a valuable coping strategy, whereas others contend that women should be made aware of sexism with the aim of "inoculating" them against it (Collins, 2002; Hunter, 1998). Increasing awareness of sexism alone, however, may have the unintended negative consequence of making women more susceptible to its harmful effects. Women in this study who were exposed to pervasive sexism, but not group affirmed, had lower self-esteem than those in the control condition.

In accordance with Self-Affirmation Theory (Steele, 1988) and the nascent group affirmation literature (Čehajić-Clancy, Effron, Halperin, Liberman, \& Ross, 2011; Derks et al., 2006; Glasford et al., 2009; Gunn \& Wilson, 2011; Sherman et al., 2007), we hypothesized that group affirmation would buffer the self-esteem of women exposed to blatant discrimination. As illustrated in Figure 1, the results of the planned comparisons 
supported this prediction. Our findings are consistent with previous research showing that women can be harmed by perceptions of pervasive sexism (Branscombe et al., 2002; McCoy \& Major, 2003; Schmitt et al, 2014), and further suggest that group affirmation can fully mitigate this risk of psychological harm.

We propose that group affirmation operated to protect self-esteem by situationally activating and boosting psychological assets and resources, thereby enabling people to cope with threats to self-integrity (Sherman et al., 2007; Steele et al., 1993). We tested two alternative possible alternative explanations for the current findings. One is consistent with the Rejection Identification Model (Branscombe et al., 1999) and the notion that the esteembuffering effect could be due to increased gender identification, rather than to group affirmation. However, we found no empirical evidence for this alternative hypothesis: gender identity (and gender liking) were not significantly higher among women in the Sexism/ Affirm condition, relative to the Sexism/No-affirm condition (see Figure 2). A second possibility is that women threatened by sexism simply disidentified from their gender group. People may distance themselves from a disadvantaged group in order to protect self-esteem, through processes such as disidentification (Allport, 1954; Tajfel \& Turner, 1986) and CORFing (cutting off reflected failure; Snyder, Lassegard, \& Ford, 1986). Again, however, there was no empirical evidence consistent with this argument. Our results suggest that the esteem-buffering effect of group affirmation among women exposed to blatant sexism was due to the psychological benefits afforded by reflecting on membership in an alternative valued group, rather than to increasing identification with, or distancing from, the threatened group.

The present study extends the group affirmation literature by demonstrating the esteembuffering effects of affirming a wide variety of types of groups (Lickel et al., 2000), including intimacy groups (62\%), task groups (19\%), and social categories (19\%). To our knowledge, only one other study (White et al., 2012) asked people to affirm groups and group values of their choice, and the researchers provided no information about the types of groups that were selected. (Participants were instructed to select a value and write about how they, and "the groups they belongs to", share the same value.) Most of the women in our study $(81 \%)$ generated intimacy and task groups, albeit this may be partly a function of the instructions employed in this study, in which participants were told to select a "group of people" with whom they felt very close, and these groups are perceived as more "grouplike" or entitative than are social categories (Lickel et al., 2000). Nevertheless, this research, along with White et al., 2012, illustrates that group affirmations operate effectively when people generate and actively affirm alternative group memberships, in addition to the threatened group itself (e.g., Sherman et al., 2007) or alternative dimensions of the threatened group (e.g., Derks et al., 2006). Future research could examine whether the type of group affirmed (i.e., intimacy groups, social categories, task groups, or loose associations; Lickel et al., 2000) moderates the effectiveness of group affirmation.

In this study, group affirmation successfully buffered the self-esteem of European-American women. Further research is needed to determine whether these findings generalize to other intergroup contexts (e.g., to ethnic minorities and other stigmatized groups, such as homosexuals, the elderly, disabled, etc.). If so, group affirmation might serve a valuable self- 
protective function for people confronting racism and other forms of discrimination. We examined the short-term benefits of group affirmation in the laboratory, permitting us to implement tight controls. Longitudinal field studies would establish the long-term benefits of this intervention. It is also noteworthy that all of the women in our sample had high stable/chronic gender identity (based on prescreening), and different results might have been obtained with women who were less connected to their gender group. In particular, selfaffirmation, rather than group affirmation, may be a more effective intervention for people who are less identified with the threatened group (Derks et al., 2011; Glasford et al., 2009). We view these topics as promising areas for future research.

With its emphasis on the individual as the unit of analysis, it is not surprising that the field of psychology has focused on affirmations of the individual self (McQueen \& Klein, 2006; Sherman \& Cohen, 2006). However, there is both individual and cultural variability in the extent to which people place importance on personal values, goals, and accomplishments (Markus \& Kitayama, 1991; Tajfel \& Turner, 1986; Triandis, 1995), and group affirmations may be more potent manipulations than self-affirmations for people who habitually define themselves via their group memberships (Derks et al., 2011; Glasford et al., 2009; White et al., 2012). Comparative studies that have measured people's initial stable level of identification with a threatened group indicate that group identity moderates the effectiveness of affirmations. For example, group affirmation is more effective at shielding highly gender-identified women from stereotype threat (Derks et al., 2011) and at reducing psychological discomfort (intragroup dissonance) among high group-identifiers (Glasford et al., 2009), and affirmations that engender a sense of social belonging may be particularly effective at protecting people from stereotype threat (Shnabel et al., 2013).

Group affirmations also may be more powerful interventions for members of collectivistic cultures, for whom group values, goals, and accomplishments are paramount, and for whom ingroup memberships and close relationships are highly self-defining (Markus \& Kitayama, 1991; Triandis, 1995; White et al., 2012). For example, in one study (White et al., 2012), Hong Kong Chinese (collectivist) and Canadian (individualist) students were threatened by reading a fictitious article that indicated that their university was ranked very poorly compared to others in the nation (social identity threat). Participants then completed a traditional self-affirmation or a group affirmation (i.e., they selected a value and explained why they and the groups they belong to share the value). The group affirmation, but not the self-affirmation, was effective in reducing defensive responses among Hong Kong Chinese, whereas the self-affirmation, but not the group affirmation, was successful among Canadians.

A relatively small body of work has explored the advantages of affirming other social aspects of the self, such as the relational self or "self-as-close-other" (Brewer \& Gardner, 1996; Chen \& Boucher, 2008), the familial self or "self-as-family-member" (Cai, Sedikides, $\&$ Jiang, 2013), and the interdependent self or culturally collectivistic self (Hoshino-Browne et al., 2005; Markus \& Kitayama, 1991). For example, Hoshino-Brown et al. (2005) developed an interdependent self-affirmation (participants selected a value for themselves and their families and explained why they shared the value) and an independent selfaffirmation (participants selected a value and explained why it uniquely described who they 
were). The interdependent, but not the independent self-affirmation, reduced a threat to selfintegrity (cognitive dissonance) among Asian-Canadians (Hoshino-Brown et al., 2005). One practical implication of this nascent corpus of research is that, to increase the likelihood of their success, different types of affirmations (self, familial, relational, group, interdependent) could be targeted to people depending on their habitual manner of construing the self (e.g.as measured by scales such as the Relational-Interdependent Self-Construal Scale [Cross et al., 2000] and the Self-Construal Scale [Singelis, 1994]), as well as their chronic or stable level of identification with the threatened group.

\section{Conclusion}

This study contributes to research that seeks to identify mechanisms that bolster the selfesteem and psychological well-being of disadvantaged group members. A group-values affirmation is a relatively simple intervention that can be implemented readily by educators, mental health counselors, and potentially, the targets of discrimination themselves (Silverman et al., 2013). The present findings illustrate the power of affirming one's group values in the context of discrimination. As with self-affirmations, group affirmations may have enduring mental and physical health benefits, especially for people who habitually define themselves via their group memberships.

\section{Acknowledgments}

\section{FINANCIAL DISCLOSURE/FUNDING:}

This research was supported by an Administrative Supplement grant from the National Health, Lung, and Blood Institute NIH R01-HL079383-S1. The first author also gratefully acknowledges the support of the Cher Wang \& Wenchi Chen Foundation.

\section{References}

Allport, G. The nature of prejudice. Cambridge, MA: Addison-Wesley; 1954.

Ayres MM, Friedman CK, Leaper C. Individual and situational factors related to young women's likelihood of confronting sexism in their everyday lives. Sex Roles. 2009; 61(7-8):449-460. [PubMed: 19784381]

Branscombe N, Schmitt M, Harvey R. Perceiving pervasive discrimination among African Americans: Implications for group identification and well-being. Journal of Personality \& Social Psychology. 1999; 77:135-149. http://dx.doi.org/10.1037/0022-3514.77.1.135.

Branscombe NR, Kobryknowicz D, Owen S, Schmitt MT. Perceiving discrimination against one's gender group has different implications for well-being in women and men. Personality and Social Psychology Bulletin. 2002; 28(2):197-210.

Brewer MB, Gardner W. Who is this 'We'? Levels of collective identity and self representations. Journal of Personality and Social Psychology. 1996; 71(1):83-93.

Cai H, Sedikides C, Jiang L. Familial self as a potent source of affirmation: Evidence from China. Social Psychological and Personality Science. 2013; 4(5):529-537.

Čehajić-Clancy S, Effron DA, Halperin E, Liberman V, Ross LD. Affirmation, acknowledgment of ingroup responsibility, group-based guilt, and support for reparative measures. Journal of Personality and Social Psychology. 2011; 101(2):256-270. [PubMed: 21639648]

Cohen GL, Aronson J, Steele CM. When beliefs yield to evidence: Reducing biased evaluation by affirming the self. Personality and Social Psychology Bulletin. 2000; 26(9):1151-1164.

Cohen GL, Garcia J, Purdie-Vaughns V, Apfel N, Brzustoski P. Recursive processes in self-affirmation: Intervening to close the minority achievement gap. Science. 2009; 324:400-403. [PubMed: 19372432] 
Collins, LH. Self-esteem inoculation: Protecting girls from the effects of sexism. In: Collins, LH.; Dunlap, MR.; Chrisler, JC., editors. Charting a new course for feminist psychology. Westport, CT: Praeger Publishers/Greenwood Publishing Group; 2002. p. 139-166.

Corbett, C.; Hill, C. Graduating to a pay gap: The earnings of women and men one year after college graduation. Washington, DC: American Association of University Women; 2012.

Creswell JD, Lam S, Stanton AL, Taylor SE, Bower JE, Sherman DK. Does self-affirmation, cognitive processing, or discovery of meaning explain cancer-related health benefits of expressive writing? Personality and Social Psychology Bulletin. 2007; 33(2):238-250. [PubMed: 17259584]

Creswell JD, Wlech W, Taylor SE, Sherman DK, Gruenewald T, Mann T. Affirmation of personal values buffers neuroendocrine and psychological stress responses. Psychological Science. 2005; 16(11):846-851. [PubMed: 16262767]

Crocker J, Major B. Social stigma and self-esteem: The self-protective properties of stigma. Psychological Review. 1989; 96(4):608-630.

Crosby F. The denial of personal discrimination. American Behavioral Scientist. 1984; 27(3):371-386.

Cross SE, Bacon PL, Morris ML. The relational-interdependent self-construal and relationships. Journal of Personality and Social Psychology. 2000; 78(4):791-808. [PubMed: 10794381]

Derks B, Scheepers D, van Laar C, Ellemers N. The threat vs. challenge of car parking for women: How self- and group affirmation affect cardiovascular responses. Journal of Experimental Social Psychology. 2011; 47(1):178-183.

Derks B, van Laar C, Ellemers N. Striving for success in outgroup settings: Effects of contextually emphasizing ingroup dimensions on stigmatized group members? Social identity and performance styles. Personality and Social Psychology Bulletin. 2006; 32(5):576-588. [PubMed: 16702152]

Dion KL. Women's reactions to discrimination from members of the same or opposite sex. Journal of Research in Personality. 1975; 9(4):294-306.

Eliezer D, Major B, Mendes W. The costs of caring: Gender identification increases threat following exposure to sexism. Journal of Experimental Social Psychology. 2010; 46(1):159-165.

Fein S, Spencer SJ. Prejudice as self-image maintenance: Affirming the self through derogating others. Journal of Personality and Social Psychology. 1997; 73(1):31-44.

Fisher, RA. The design of experiments. Hafner: Edinburgh; 1966.

Fischer AR, Holtz K. Perceived discrimination and women's psychological distress: The roles of collective and personal self-esteem. Journal of Counseling Psychology. 2007; 54(2):154-164.

Foster MD. Utilization of global attributions in recognizing and responding to gender discrimination among college women. Current Psychology: A Journal for Diverse Perspectives on Diverse Psychological Issues. 2000; 19(1):57-69.

Gervais SJ, Hillard AL, Vescio TK. Confronting sexism: The role of relationship orientation and gender. Sex Roles. 2010; 63(7-8):463-474.

Glasford DE, Dovidio JF, Pratto F. I continue to feel so good about us: In-group identification and the use of social identity-enhancing strategies to reduce intragroup dissonance. Personality and Social Psychology Bulletin. 2009; 35(4):415-427. [PubMed: 19141621]

Gonzalez, R. Contrasts and post hoc tests. 2013. Retrieved from: http://www-personal.umich.edu/ $\sim$ gonzo/coursenotes/file3.pdf

Gunn GR, Wilson AE. Acknowledging the skeletons in our closet: The effect of group affirmation on collective guilt, collective shame, and reparatory attitudes. Personality and Social Psychology Bulletin. 2011; 37(11):1474-1487. [PubMed: 21734164]

Hoshino-Browne E, Zanna AS, Spencer SJ, Zanna MP, Kitayama S, Lackenbauer S. On the cultural guises of cognitive dissonance: The case of Easterners and Westerners. Journal of Personality and Social Psychology. 2005; 89(3):294-310. [PubMed: 16248715]

Hunter C. The effect of a gender discrimination awareness training program on college students' perception of micro-inequities, self-efficacy and self-esteem. Dissertation Abstracts International. 1998; 59(4-B):1914.

Johns M, Schmader T, Martens A. Knowing is half the battle: Teaching stereotype threat as a means of improving women's math performance. Psychological Science. 2005; 16:175-179. [PubMed: 15733195] 
Jones PR. Reducing the impact of stereotype threat on women's math performance: Are two strategies better than one? Electronic Journal of Research in Educational Psychology. 2011; 9(2):587-616. [PubMed: 22545058]

Keppel, G.; Saufley, WH.; Tokunaga, H. Introduction to design and analysis: A student's handbook. New York: Worth Publishers; 1992.

Legault L, Al-Khindi T, Inzlicht M. Preserving integrity in the face of performance threat: Selfaffirmation enhances neurophysiological responsiveness to errors. Psychological Science. 2012; 23(12):1455-1460. [PubMed: 23090755]

Lickel B, Hamilton DL, Wieczorkowska G, Lewis A, Sherman SJ, Uhles AN. Varieties of groups and the perception of group entitativity. Journal of Personality and Social Psychology. 2000; 78:223246. [PubMed: 10707331]

Logel C, Walton GM, Spencer SJ, Iserman EC, von Hippel W, Bell AE. Interacting with sexist men triggers social identity threat among female engineers. Journal of Personality and Social Psychology. 2009; 96(6):1089-1103. [PubMed: 19469589]

Luhtanen R, Crocker J. A collective self-esteem scale: Self-evaluation of one's social identity. Personality and Social Psychology Bulletin. 1992; 18:302-318.

Markus HR, Kitayama S. Culture and the self: Implications for cognition, emotion, and motivation. Psychological Review. 1991; 98(2):224-253.

Major, B.; Schmader, T. Coping with stigma through psychological disengagement. In: Swim, J.; Stangor, C., editors. Prejudice: The target's perspective. San Diego, CA: The Academic Press; 1998. p. 219-241.

McCoy SK, Major B. Group identification moderates emotional responses to perceived prejudice. Personality and Social Psychology Bulletin. 2003; 29(8):1005-1017. [PubMed: 15189619]

McGregor I, Haji R, Kang S. Can ingroup affirmation relieve outgroup derogation? Journal of Experimental Social Psychology. 2008; 44(5):1395-1401.

McQueen A, Klein WP. Experimental manipulations of self-affirmation: A systematic review. Self and Identity. 2006; 5(4):289-354.

Nadal, KL.; Haynes, K. The effects of sexism, gender micro aggressions, and other forms of discrimination on women's mental health and development. In: Lundberg-Love, PK.; Nadal, KL.; Paludi, MA., editors. Women and mental disorders. Vol. 1-4. Santa Barbara, CA: Praeger/ABCCLIO; 2012. p. 87-101.

National Center for Education Statistics. National Post-Secondary Aid Study. Washington, DC: U.S. Department of Education; 2009. Digest of Educational Statistics: 2011. http://nces.ed.gov/ programs/digest/d11/ [Retrieved June 15, 2013]

Nicholson S. 'So you row, do you? You don't look like a rower' An account of medical students' experience of sexism. Medical Education. 2002; 36(11):1057-1063. [PubMed: 12406266]

Nutt, RL. Prejudice and discrimination against women based on gender bias. In: Chin, J., editor. The psychology of prejudice and discrimination: A revised and condensed edition. Santa Barbara, CA: Praeger/ABD-CLIO; 2010. p. 125-137.

Pascoe EA, Smart Richman L. Perceived discrimination and health: A meta-analytic review. Psychological Bulletin. 2009; 135(4):531-554. [PubMed: 19586161]

Pettit NC, Lount RB Jr. Looking down and ramping up: The impact of status differences on effort in intergroup contexts. Journal of Experimental Social Psychology. 2010; 46(1):9-20.

Pierce, T. Comparisons between treatment means in ANOVA. 2003. Retrieved from: http:// www.radford.edu/ tpierce/610\%20files/Data\%20Analysis\%20for\%20Professional \%20Psychologists/Comparisons\%20in\%20ANOVA.pdf

Rosenberg, M. Socetiy and the adolescent self-image. Princeton: Princeton University Press; 1965.

Schmitt MT, Branscombe NR, Postmes T. Women's emotional responses to the pervasiveness of gender discrimination. European Journal of Social Psychology. 2003; 33(3):297-312.

Schmitt MT, Branscombe NR, Postmes T, Garcia A. The consequences of perceived discrimination for psychological wellbeing: A meta-analysis. Psychological Bulletin. 2014

Seltman, HJ. Contrasts and custom hypothesis tests. Experimental design and analysis. 2013. Retrieved from: http://www.stat.cmu.edu/ hseltman/309/Book/Book.pdf 
Shelton J, Richeson JA, Salvatore J. Expecting to be the target of prejudice: Implications for interethnic interactions. Personality and Social Psychology Bulletin. 2005; 31(9):1189-1202. [PubMed: 16055639]

Sherman DK, Bunyan DP, Creswell DJ, Jaremka LM. Psychological vulnerability and stress: The effects of self-affirmation on sympathetic nervous system responses to naturalistic stressors. Health Psychology. 2009; 28(5):554-562. [PubMed: 19751081]

Sherman, DK.; Cohen, GL. The psychology of self-defense: Self-affirmation theory. In: Zanna, MP., editor. Advances in experimental social psychology. Vol. 38. San Diego, CA: Elsevier Academic Press; 2006. p. 183-242.

Sherman DK, Cohen GL, Nelson LD, Nussbaum A, Bunyan DP, Garcia J. Affirmed yet unaware: Exploring the role of awareness in the process of self-affirmation. Journal of Personality and Social Psychology. 2009; 97(5):745-764. [PubMed: 19856999]

Sherman DK, Hartson KA, Binning KR, Purdie-Vaughns V, Garcia J, Taborsky-Barba S, Cohen GL. Deflecting the trajectory and changing the narrative: How self-affirmation affects academic performance and motivation under identity threat. Journal of Personality and Social Psychology. 2013; 104(4):591-618. [PubMed: 23397969]

Sherman DK, Kinias Z, Major B, Kim HS, Prenovost M. The group as a resource: Reducing biased attributions for group success and failure via group affirmation. Personality and Social Psychology Bulletin. 2007; 33(8):1100-1112. [PubMed: 17630262]

Shnabel N, Purdie-Vaughns V, Cook JE, Garcia J, Cohen GL. Demystifying values-affirmation interventions: Writing about social belonging is a key to buffering against identity threat. Personality and Social Psychology Bulletin. 2013; 39(5):663-676. [PubMed: 23478675]

Silverman A, Logel C, Cohen GL. Self-affirmation as a deliberate coping strategy: The moderating role of choice. Journal of Experimental Social Psychology. 2013; 49(1):93-98.

Singelis TM. The measurement of independent and interdependent self-construals. Personality and Social Psychology Bulletin. 1994; 20(5):580-591.

Sipe S, Johnson C, Fisher DK. University students' perceptions of gender discrimination in the workplace: Reality versus fiction. Journal of Education for Business. 2009; 84(6):339-349.

Snyder CR, Lassegard M, Ford CE. Distancing after group success and failure: Basking in reflected glory and cutting off reflected failure. Journal of Personality And Social Psychology. 1986; 51(2): 382-388.

Steele, CM. The psychology of self-affirmation: Sustaining the integrity of the self. In: Berkowitz, L., editor. Advances in experimental social psychology. Vol. 21. New York: Academic Press; 1988. p. 261-302.

Steele CM, Aronson J. Stereotype threat and the intellectual test performance of African-Americans. Journal of Personality and Social Psychology. 1995; 69(5):797-811. [PubMed: 7473032]

Steele CM, Spencer SJ, Lynch M. Self-image resilience and dissonance: The role of affirmational resources. Journal of Personality and Social Psychology. 1993; 64(6):885-896. [PubMed: 8326471]

Swim JK, Hyers LL, Cohen LL, Ferguson MJ. Everyday sexism: Evidence for its incidence, nature, and psychological impact from three daily diary studies. Journal of Social Issues. 2001; 57(1):3153.

Tajfel, H.; Turner, JC. The social identity theory of intergroup behavior. In: Austin, W.; Worchel, S., editors. The social psychology of intergroup relations. Monterey: Brooks/Cole; 1986. p. 7-24.

Taylor DM, Wright SC, Moghaddam FM, Lalonde RN. The personal/group discrimination discrepancy: Perceiving my group, but not myself, to be a target for discrimination. Personality and Social Psychology Bulletin. 1990; 16(2):254-262.

Triandis HC. Is recent psychology not pertinent for the study of values? Psyccritiques. 1995; 40(4): 339-340.

U.S. Department of Labor, Bureau of Labor Statistics. Women in the Labor Force in 2010. 2011. Retrieved from http://www.dol.gov/wb/factsheets/Qf-laborforce-10.htm

White K, Argo JJ, Sengupta J. Dissociative versus associative responses to social identity threat: The role of consumer self-construal. Journal of Consumer Research. 2012; 39(4):704-719. 
Zhang, S.; Schmader, T.; Forbes, C. The effects of gender stereotypes on women's career choice: Opening the glass door. In: Barreto, M.; Ryan, MK.; Schmitt, MT., editors. The glass ceiling in the 21st century: Understanding barriers to gender equality. Washington, DC: American Psychological Association; 2009. p. 125-150. 


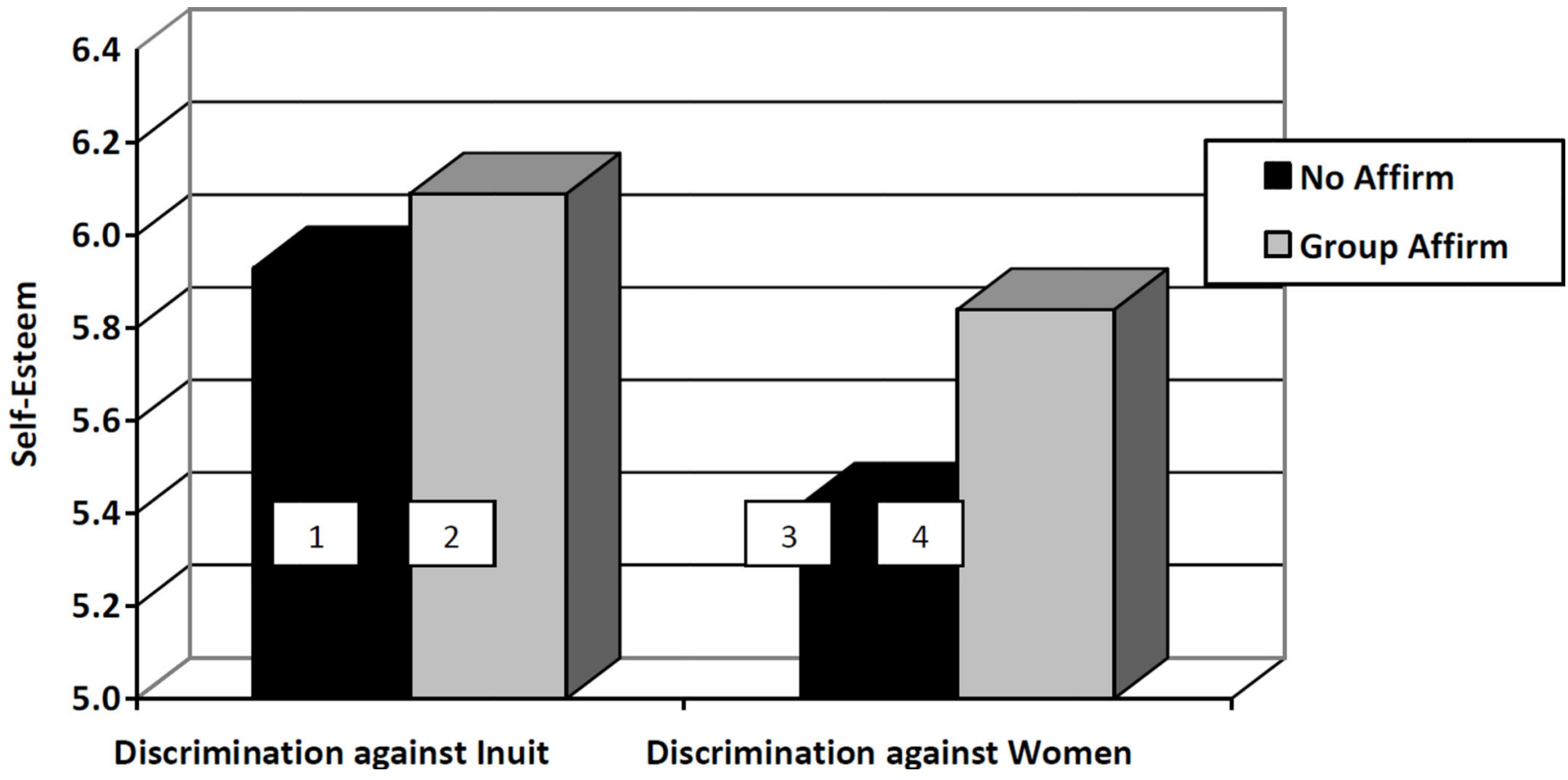

Figure 1.

Mean self-esteem scores by type of article and affirmation condition. 


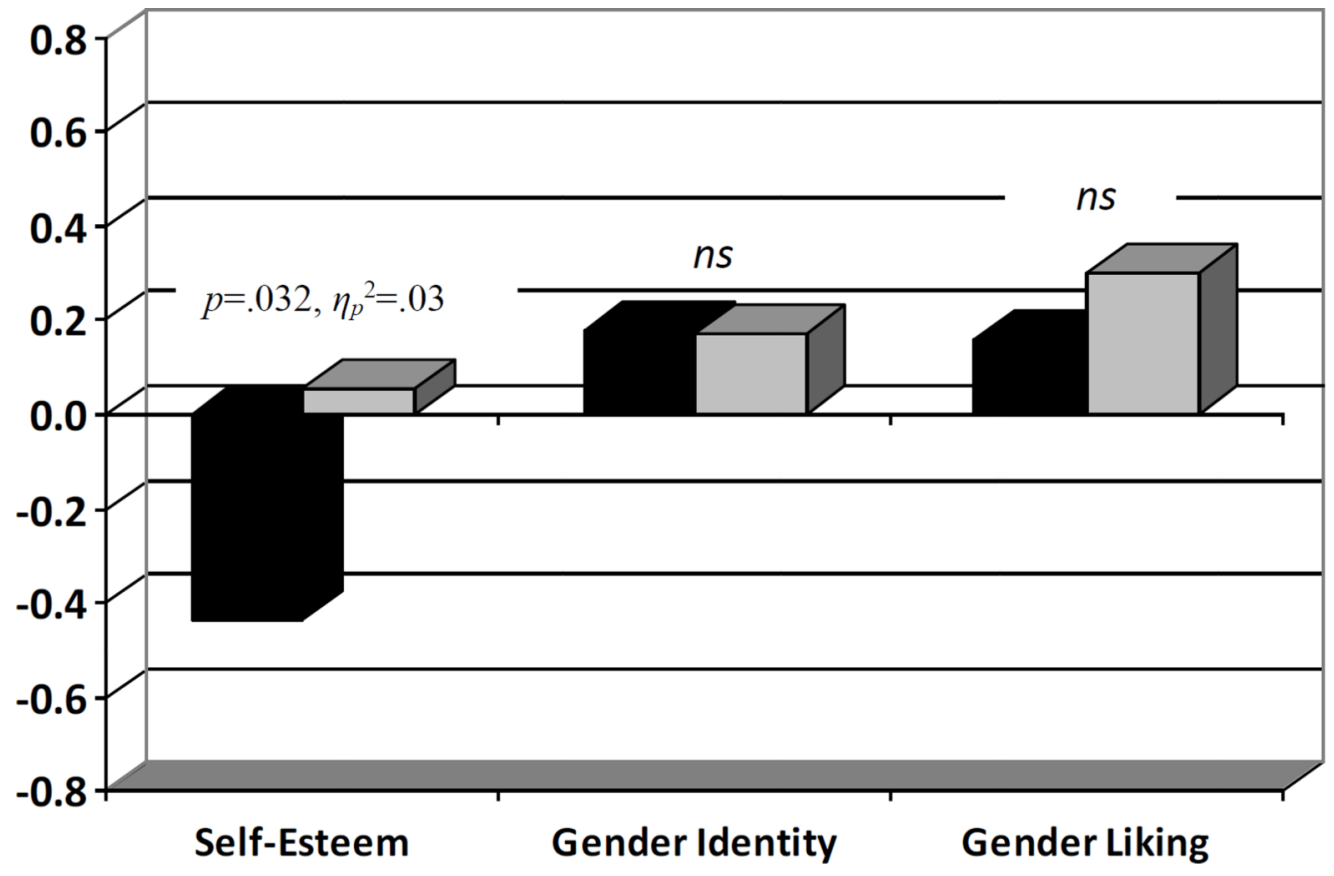

No Affirm $\square$ Group Affirm

Figure 2.

Mean standardized self-esteem, gender identity, and gender liking scores for women who read about sexism and were either group-affirmed or non-affirmed. 
Spencer-Rodgers et al.

Page 21

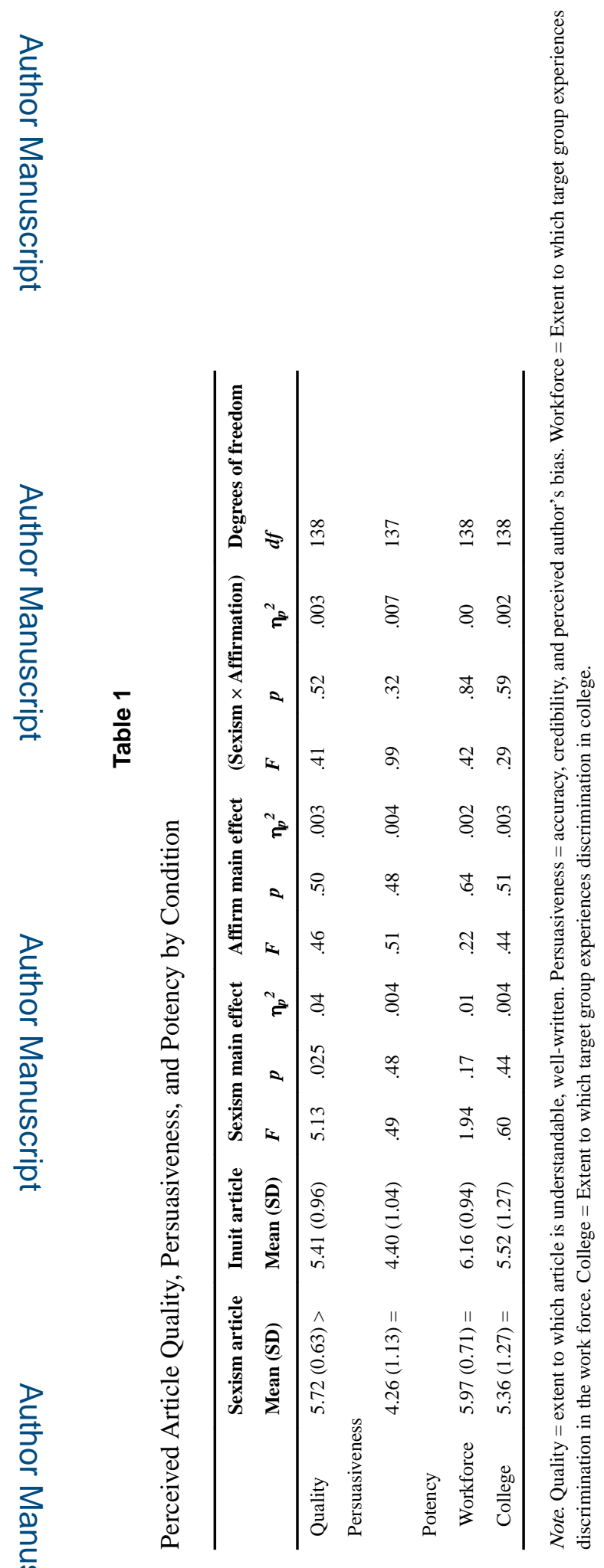

Self Identity. Author manuscript; available in PMC 2017 February 26. 